\title{
Cognitive failure: Everyday and laboratory performance
}

\author{
MARYANNE MARTIN \\ University of Oxford, Oxford, OX1 3UD, England
}

\begin{abstract}
The hypothesis that everyday cognitive failures are associated over individuals with levels of focused-attention performance was examined in a series of experiments. Everyday cognitive failure was assessed by the Cognitive Failures Questionnaire, and focused-attention performance was assessed using the Stroop, reverse Stroop, and dichotic-listening paradigms, together with the Embedded Figures Test. No reliable association between the two types of measure was observed. In addition, questionnaire results indicated a significant relation between reported cognitive failure and memory performance (using the Short Inventory of Memory Experiences and the Everyday Memory Questionnaire) but not attentional performance (using the Everyday Attention Questionnaire).
\end{abstract}

In the last 10 years, there has been a movement toward investigating practical aspects of memory and cognition (see Baddeley, 1981; Gruneberg \& Morris, 1979; Gruneberg, Morris, \& Sykes, 1978; Neisser, 1976, 1982). This has on occasion led to a trend away from well controlled, although sometimes somewhat artificial, laboratory studies toward more ecologically valid field studies. This paper tries to link these two approaches by examining the relationship between laboratory measures of performance and cognitive failures that occur in everyday life. An everyday cognitive failure is a cognitively based error that occurs during the performance of a task that a person is normally successful in executing. For example, most people have had the experience of at least starting to throw away something that they meant to keep, while simultaneously retaining the thing that they meant to throw out.

The study of everyday cognitive failures has attracted interest for three reasons. First, for certain dangerous tasks such as flying, the occurrence of cognitive failure can have serious effects (see examples analyzed by Reason \& Mycielska, 1982). Second, even when the external consequences of cognitive failure are not important, the phenomenon may still be important for what it reveals about a person's psychological functioning. For example, Broadbent, Cooper, Fitzgerald, and Parkes (1982) found that individuals who make a large number of cognitive failures are particularly susceptible to the adverse psychological effects of a high-stress environ-

The author is grateful to Sara M. Dickson for testing the subjects in Experiments 1-5 and in the first group of Experiment 6, to Johanna C. Ward and Gregory V. Jones for testing the second and third groups, respectively, of Experiment 6, and to the Science and Engineering Research Council and the Medical Research Council for their support of the research. Requests for reprints should be addressed to Maryanne Martin, Department of Experimental Psychology, University of Oxford, South Parks Road, Oxford OX1 3UD, England. ment. Third, analysis of the types of cognitive failures that commonly occur may shed light on the way in which higher order mental functions are organized.

To assess the incidence of everyday cognitive failures directly, it seems necessary to use a self-report technique. Two major self-report methods have been employed, diaries and questionnaires. The diary method, in which subjects keep a daily record over a period of some weeks of their cognitive failures, allows a wide range of naturally occurring examples of cognitive failure to be collected (e.g., Reason, 1977, 1979). Such collations are akin to those of verbal errors (see Fromkin, 1973, 1980; Meringer, 1908; Meringer \& Mayer, 1895). The questionnaire method has been used in particular for examining various aspects of memory. Herrmann (1982) reviews 14 such questionnaires. Among these, three deal with everyday failures of cognition that are not restricted to memory. Two were compiled by Reason, the Error Proneness Questionnaire (EPQ) and the Slips of Action Inventory (SAI), based on his earlier questionnaire studies (Reason, 1977, 1979, in press). The third, which will be employed here, is the self-report questionnaire developed by Broadbent et al. (1982). This is termed the Cognitive Failures Questionnaire (CFQ). The CFQ contains 25 items that cover failures of perception, memory, and motor function. Respondents indicate for each question the frequency with which that type of cognitive failure has occurred to them during the last 6 months, on a 5-point scale ranging from "never" (1) to "very often" (5).

In addition to the above-mentioned self-report indexes, it would also be advantageous to possess an objective laboratory measure that correlates with the incidence of cognitive failure in everyday life. This is for two reasons. First, the use of the latter might be preferable in some situations, such as personnel selection, because it would not be affected by biases in the extent to which a person is willing to report the occurrence of 
cognitive failures. Second, the nature of any laboratory task that does prove to be related to everyday cognitive failure is likely to provide an insight into the specific cognitive mechanisms that are responsible for producing cognitive failures. One class of experimental tasks that might in principle prove relevant to cognitive failure are those that test memory. However, Broadbent et al. (1982) have found no significant correlations between individuals' CFQ scores and performance on several such measures: immediate memory for nine-item lists, longterm memory for categorized material, performance in the Williams delayed recall test, and the magnitudes of suffix and articulatory suppression effects.

The hypothesis to be tested here is that everyday cognitive failure is associated with difficulties in focusedattention performance. The relevance of attention in this area has recently been pointed to by Reason (in press): "There is at least one, largely neglected, class of everyday events that can yield important clues as to the role of attention in the guidance of routinised behaviour, namely the slips of action that seemingly arise from the misdirection of focal attention." A series of experiments was carried out to test the hypothesis that, over individuals, the reported incidence of cognitive failure would be negatively related to objective performance in a focusedattention paradigm. The first experiment employed the widely used Stroop method (e.g., Dyer, 1973; Martin, $1978 \mathrm{~b}$; Stroop, 1935) to assess individuals' ability to focus their attention on simple color naming.

\section{EXPERIMENT 1}

\section{Method}

This experiment tested 32 members of the Oxford subject panel. Following administration of the CFQ, subjects were instructed to sort packs of 30 cards into piles on the basis of each card's ink color. There were six colors (yellow, orange, green, blue, purple, black). In the experimental condition, the ink formed the name of one of the colors. Pilot observations had indicated that the largest Stroop effects were obtained not when all color names differed from the ink in which they were written, but when approximately one-half did. Thus for half of the cards ink and name were conflicting, and for the other half they were matching. In the control condition, the ink formed a row of Xs. Subjects performed the sorting either in silence or while counting aloud from 1 to 10 .

\section{Results and Discussion}

The magnitude of the Stroop effect was defined as experimental cards minus control cards sorting time, divided by control sorting time. The correlation between CFQ score and Stroop effect did not reach significance for performance in either the silent $[\mathrm{r}(30)=.00]$ or the counting $[\mathrm{r}(30)=.23]$ conditions. There was, however, a significant correlation $[\mathrm{r}(30)=-.38, \mathrm{p}<.05]$ between the Stroop effect and one of the products of an early factor analysis of the CFQ, Factor B, for performance while counting, although not while silent $[\mathrm{r}(30)=-.24]$. In addition, there were no significant correlations between CFQ score and the absolute card sorting time for either the experimental cards [silent condition, $\mathrm{r}(30)=-.04$; counting condition, $\mathrm{r}(30)=-.11]$ or the control cards [silent condition, $\mathrm{r}(30)=-.07$; counting condition, $\mathrm{r}(30)=.12]$.

A second experiment was carried out in order to assess the reliability of the above findings.

\section{EXPERIMENT 2}

\section{Method}

The method of this experiment was the same as that of Experiment 1, except that a new set of 32 subjects was tested.

\section{Results and Discussion}

As before, there was no significant correlation between the Stroop effect and overall CFQ score for performance in either the silent $[\mathrm{r}(30)=.03]$ or the counting $[\mathrm{r}(30)=$ .02] condition. In this experiment, however, the correlations between the Stroop effect and Factor B were also nonsignificant for both silent and counting performance $[\mathrm{r}(30)=.11$ and -.09 , respectively $]$. In addition, there were no significant correlations beween CFQ score and the absolute card sorting time for either the experimental cards [silent condition, $\mathrm{r}(30)=-.14$; counting condition, $\mathrm{r}(30)=-.13$ ] or the control cards [silent condition, $\mathrm{r}(30)=-.16$; counting condition, $\mathrm{r}(30)=-.13$ ]

A third experiment examined performance in a Stroop paradigm in which the subjects' task was the reverse of the normal one.

\section{EXPERIMENT 3}

\section{Method}

A further set of 32 members of the Oxford subject panel was tested. Following administration of the CFQ, subjects sorted packs of 30 cards on the basis of the six color names (identities as before) written on the cards. The names were written in inks that in the experimental condition included each of these colors (with equal numbers of cards having conflicting ink colors and names and matching ink colors and names) and in the control condition were all a different color, brown. Subjects performed the sorting either in silence or while continuously repeating aloud the syllable "blah."

\section{Results and Discussion}

The correlation between CFQ score and the size of the reverse-procedure Stroop effect did not reach significance for performance in either the silent $[\mathrm{r}(30)=.10]$ or the continuous articulation $[\mathrm{r}(30)=-.17]$ conditions. In addition, there were no significant correlations between CFQ score and the absolute card sorting time for either the experimental cards [silent condition, $\mathrm{r}(30)=.02$; continuous articulation condition, $\mathrm{r}(30)=$ -.19 ] or the control cards [silent condition, $\mathrm{r}(30)=-.10$; continuous articulation condition, $\mathrm{r}(30)=-.04]$.

The first three experiments failed to demonstrate a reliable relation between CFQ and Stroop performance. Accordingly, a further experiment was carried out using 
a different focused-attention task, dichotic listening, with an ordered recall procedure similar to that of Martin (1978a).

\section{EXPERIMENT 4}

\section{Method}

The subjects were 20 members of the Oxford subject panel. On each trial, subjects were presented with 4 successive pairs of digits at a rate of 2 pairs/sec, with one member of each pair being presented to each ear. They were instructed to concentrate their attention on the words of only one side. Subsequently, subjects attempted to recall either the attended words followed by the unattended words, or the reverse.

\section{Results and Discussion}

The correlations between CFQ scores and each of the experimental measures were nonsignificant [for attended words recalled first and second, $r(18)=.28$ and .01 , respectively; for unattended words recalled first and second, $\mathrm{r}(18)=.08$ and .24 , respectively].

In view of the failure to establish an association between CFQ score and performance on an experimental focused-attention task, a further study was carried out using a standardized test of focused-attention ability, the Embedded Figures Test.

\section{EXPERIMENT 5}

\section{Method}

A further 20 members of the Oxford subject panel were administered the CFQ followed by the Embedded Figures Test (Witkin, Oltman, Raskin, \& Karp, 1971). In this test, the subject's task is to locate a previously seen figure within a larger matrix. Two measures can be derived from this test: the total time taken to find the figure, and the number of exposures of the original figure that were necessary during searching.

\section{Results and Discussion}

The CFQ scores were not significantly correlated with either the total time taken to find embedded figures $[r(18)=.00]$ or the number of exposures of the original figure that were necessary $[\mathrm{r}(18)=.16]$.

Finally, in view of the failure to find any relationship between CFQ and laboratory measures of focused attention, it was considered important to determine whether there was any relationship between the CFQ and subjective measures of attention. For this reason, correlations were computed between the CFQ and Martin's Everyday Attention Questionnaire (EAQ; see Martin \& Jones, in press). In addition, in view of the earlier interest in the relationship between the CFQ and memory performance, correlations were also computed between the CFQ and two recent subjective memory measures. These were Martin's Everyday Memory Questionnaire (EMQ; Martin \& Jones, in press) and the Short Inventory of Memory Experiences (SIME; Herrmann, 1982; Herrmann \& Neisser, 1978).

\section{EXPERIMENT 6}

\section{Method}

In this study, three separate groups of subjects were studied. The first and second comprised 20 and 40 Oxford University undergraduates, respectively, while the third comprised 30 Bristol University undergraduates. All three groups were administered the EMQ, EAQ, and CFQ (in that order); the first group was also administered the SIME.

\section{Results and Discussion}

In each case, there were no significant correlations between CFQ scores and EAQ scores $[\mathrm{r}(18)=.06$, $\mathrm{r}(38)=-.08, \mathrm{r}(28)=.03$, for the first, second, and third groups, respectively]. However, there were significant correlations between the CFQ and EMQ $[\mathrm{r}(18)=-.64$, $\mathrm{p}<.01 ; \mathrm{r}(38)=-.30, \mathrm{p}<.06 ; \mathrm{r}(28)=-.53, \mathrm{p}<.01]$. In addition, for the first group, the correlation between CFQ and overall SIME F-scale score was $\mathrm{r}(18)=.74$ $(\mathrm{p}<.01)$. The last result is comparable with Reason's finding (see Broadbent et al., 1982) of a correlation of $r(92)=.59(p<.01)$ for the same measures.

\section{GENERAL DISCUSSION}

The experiments reported here failed to demonstrate a reliable relation between the incidence of cognitive failure in everyday life, as assessed by the CFQ, and performance on focused-attention tasks in the laboratory. Martin has recently found the latter to be correlated with EAQ scores (Martin \& Jones, in press), and it is thus not unexpected that these also were found here to be not significantly related to CFQ scores.

On the other hand, significant correlations were observed between the CFQ and two different memory questionnaires, the SIME and the EMQ. As noted earlier, Broadbent et al. (1982) did not find significant relations between CFQ scores and several different laboratory measures of memory performance. One possible explanation of this difference is that the exercise of memory in everyday life relies critically upon processes that are not generally tapped by laboratory tasks. One area of memory that has been neglected in the search for a relation between CFQ and a laboratory measure of memory is that of incidental learning. This may prove particularly fruitful, because although memory questionnaires in general do not correlate well with objective performance, the EMQ does correlate with recall following incidental learning. In a study by Martin, Ward, and Clark (in press), the EMQ was administered to all subjects. Individuals who reported better everyday memory remembered more previously presented trait words, when they were unexpectedly asked to recall them $[\mathrm{r}(38)=.36, \mathrm{p}<.05]$.

The correlations between CFQ and memory questionnaires observed here are reassuring for accounts of cognitive failure that invoke memory models. A comparable relation has also been found by Reason between his SAI and SIME, reported in Broadbent et al. (1982). Perhaps the best known of the memory accounts is that of Norman (1982), which is based on the notion of the schema, an organized memory unit. Norman classifies cognitive failures into three major categories: errors in the formation of an intention, faulty activation of a schema, and faulty triggering. This type of analysis suggests that objective correlates of the CFQ are more likely to be found in memory tasks that involve greater use of schemata, such as story recall. So far, the memory tasks studied in relation to the CFQ have mostly involved learning lists of unrelated material, in which the potential role of schemata is diminished. 
Finally, it should be noted that the experimental tasks employed here were instances of focused-attention rather than distributed-attention paradigms. That is, in each case, the participant's task was to concentrate upon a single channel of information designated by the experimenter. In a distributed-attention task, alternatively termed a divided-attention task (e.g., Johnstone \& Dark, 1982), on the other hand, the participant's ability to process two or more channels concurrently is measured. It is possible in principle that cognitive failures arise from difficulties in distributing rather than in focusing attention. Consistent with this, there is some evidence that CFQ scores are related to levels of dual-task (but not corresponding single-task) performance (Harris \& Wilkins, 1982; Martin \& Jones, in press).

This distinction between focused and distributed attention becomes clearer when attentional constraints are described within the terms of production-system theory (e.g., Allport, $1979,1980)$. A production system (Newell, 1973) consists of a set of productions, or rules, that act upon a data base. Two problems can occur if a number of productions are executed in parallel (Anderson, 1976). First, cross-talk can occur due to imperfect segregation of the different productions. This is essentially the problem of inadequate focusing of attention. Second, it is necessary to implement metarules, production rules that have other productions as their arguments, in order to organize the various productions necessary for the achievement of higher order goals (e.g., Hayes-Roth \& Lesser, 1977). Inadequate metarules will give rise to problems in distributing attention. Thus it appears, taking together the results described here and those of Martin and Jones (in press), that high levels of cognitive failure are a consequence of inadequate metarules and not of increased cross-talk.

\section{REFERENCES}

Allport, D. A. Conscious and unconscious cognition: A computational metaphor for the mechanism of attention and integration. In L.-G. Nilsson (Ed.), Perspectives on memory research. Hillsdale, N.J: Erlbaum, 1979.

Allport, D. A. Attention and performance. In G. Claxton (Ed.), Cognitive psychology: New directions. London: Rouitledge \& Kegan Paul, 1980.

ANDE Rson, J. R. Language, memory and thought. Hillsdale, N.J: Erlbaum, 1976.

Baddeley, A. D. The cognitive psychology of everyday life. British Journal of Psychology, 1981, 72, 257-269.

Broadbent, D. E., Cooper, P. E., Fitzaerald, P., \& Parkes, K. R. Cognitive Failures Questionnaire (CFQ) and its correlates. British Journal of Clinical Psychology, 1982, 21, 1-16.

Dyer, F. N. The Stroop phenomenon and its use in the study of perceptual, cognitive, and response processes. Memory \& Cognition, 1973, 1, 106-120.

Fromkin, V. A. Speech errors as linguistic evidence. The Hague: Mouton, 1973.

Fromkin, V. A. Errors in linguistic performance: Slips of the tongue, ear, pen and hand. New York: Academic Press, 1980.

Gruneberg, M., \& Morris, P. Applied problems in memory. New York: Academic Press, 1979.

Gruneberg, M., Morris, P., \& Sykes, R. (Eds.). Practical aspects of memory. London: Academic Press, 1978.

Harris, J. E., \& Wilkins, A. J. Remembering to do things:
A theoretical framework and an illustrative experiment. Human Learning, 1982, 1, 123-136.

HAyes-Roth, F., \& Lesser, V. R. Focus of attention in the HEARSAY-II speech understanding system. Fifth International Joint Conference on Artificial Intelligence. Cambridge, Mass: M.I.T. Press, 1977.

Herrmann, D. J. Know thy memory: The use of questionnaires to assess and study memory. Psychological Bulletin, 1982, 92, 434-452.

HerrmanN, D. J., \& Neisser, U. An inventory of everyday memory experiences. In M. A. Gruneberg, P. E. Morris, \& R. N. Sykes (Eds.), Practical aspects of memory. London: Academic Press, 1978.

Johnstone, W. A., \& DARK, V. J. In defense of intraperceptual theories of attention. Journal of Experimental Psychology: Human Perception and Performance, 1982, 8, 407-421.

MARTin, M. Retention of attended and unattended auditorily and visually presented material. Quarterly Journal of Experimental Psychology, 1978, 30, 187-200. (a)

MarTin, M. Speech recoding in silent reading. Memory \& Cognition, 1978, 6, 108-114. (b)

Martin, M., \& Jones, G. V. Cognitive failures in everyday life. In J. E. Harris \& P. E. Morris (Eds.), Everyday memory, actions and absent-mindedness. London: Academic Press, in press.

Martin, M., Ward, J. C., \& Clark, D. M. Neuroticism and the recall of positive and negative personality information. Behaviour Research and Therapy, in press.

Meringer, R. Aus dem Leben der Sprache: Versprechen, Kindersprache, Nachahmungstrieb. Berlin: Behr's Verlag, 1908.

Meringer, R., \& Mayer, K. Versprechen und Verlesen: Eine psychologisch-linguistische Studie. Stuttgart: Goschen'sche Verlagschandlung, 1895.

Neisser, U. Cognition and reality. San Francisco: Freeman, 1976.

NeISSER, U. (Ed.). Memory observed: Remembering in natural contexts. San Francisco: Freeman, 1982.

Newell, A. Production systems: Models of control structures. In W. Chase (Ed.), Visual information processing. New York: Academic Press, 1973.

Norman, D. A. Categorization of action slips. Psychological Review, 1981, 88, 1-15.

Reason, J. T. Skill and error in everyday life. In M. J. A. Howe (Ed.), Adult learning. London: Wiley, 1977.

REASON, J. T. Actions not as planned: The price of automatization. In G. Underwood \& R. Stevens (Eds.), Aspects of consciousness (Vol. 1). London: Academic Press, 1979.

Reason, J. T. Lapses of attention. In R. Parasuraman, R. Davies, \& J. Beatty (Eds.), Varieties of attention. New York: Academic Press, in press.

Reason, J. T., \& Mycielska, K. Absent-minded? The psychology of mental lapses and everyday errors. Englewood Cliffs, N.J: Prentice-Hall, 1982.

Stroop, J. R. Studies of interference in serial verbal reactions. Journal of Experimental Psychology, 1935, 18, 643-662.

Witkin, H. A., Oltman, P. K., Raskin, E., \& KarP, S. A. A manual for the Embedded Figures Test. Palo Alto, Calif: Consulting Psychologists Press, 1971.

(Received for publication February 28, 1983.) 